Relatos de Experiências 


\section{A educação e os mitos no século XXI: Narciso, Eco e Sísifo estão na escola}

Claudecir dos Santos*

Resumo: O presente artigo relata alguns momentos de estudos realizados durante a capacitação para professores promovida pela Universidade Comunitária da Região de Chapecó - Unochapecó -, em parceria com a $4^{\text {a }}$ gerência de estudos do Estado de Santa Catarina nos anos de 2007 e 2008. Em algumas dessas capacitações, os professores da rede pública de educação, além de envolverem-se com teorias educacionais e participarem de oficinas, usaram o momento para fazer desabafos. A partir desses sintomas e sinais, organizou-se uma oficina sobre a educação e os mitos. Tendo como referência os mitos de Eco, Narciso e Sísifo, os professores apresentaram uma leitura crítica de suas experiências educacionais. O objetivo deste trabalho, portanto, é fazer um registro dessas reflexões.

Palavras-chave: Educação; Formação de Professores; Mitos.

Abstract: This paper presents some moments of studies conducted during a teacher's training program organized by Universidade Comunitária da Região de Chapecó - Unochapecó in partnership with the $4^{\text {a }}$ Secretariat of Studies of the State of Santa Catarina in the years of 2007 and 2008. In some of the events, teachers of the public system of education, besides

* Possui Graduação em Filosofia (Unoesc, 2002), Especialização em Ética e Filosofia Política (Unochapecó, 2004), Mestrado em Educação (UPF, 2009). É doutorando em Filosofia (Unisinos desde 2010). É professor nas disciplinas de Filosofia e Sociologia no Ensino Médio Público do Estado de Santa Catarina e no Ensino Superior na Unochapecó - Chapecó/SC. E-mail: claudecirs@unochapeco.edu.br. 
studying some theories and participating in workshops, used the moment to talk about their indignation at the educational system. From those signs and symptoms, a workshop on education and myths was organized. Based upon the myths of Echo, Narcissus and Sisyphus, the teachers presented a critical reading of their educational experiences. The aim of this paper, therefore, is to record those reflections.

Keywords: Education; Teacher's training; Myths.

\section{Introdução}

Embora as palavras de ordem sejam: melhorar o ensino, as medidas tomadas nem sempre têm a clareza que deveriam ter. Superar o sistema tradicional de ensino, recriar o modelo educativo para transformar as nossas escolas, qualificar e valorizar os professores, essas e tantas outras possibilidades são enunciadas cotidianamente. Por que, então, a chamada crise educacional não é superada?

É sabido que todo o aprendizado se dá numa rede de relações complexas, embora tenha seu ponto de partida nas aptidões cognitivas do aprendiz, nas influências culturais, ambientais, genéticas etc., a complexidade dessas relações aumenta na medida em que as capacidades de aprendizagem também se desenvolvem em graus e temporalidades diferentes. Nesse sentido, a educação não pode ignorar essa realidade, como também não pode ignorar as transformações políticas, econômicas, sociais e culturais que estão ocorrendo a todo instante por todas as partes do planeta, contudo não pode perder de vista ideais pedagógicos construídos com fins a serem alcançados. Daí, o tamanho desafio que se apresenta ao professor do século XXI.

Em relação a ideais pedagógicos, Fernando Savater em seu livro $O$ Valor de Educar, chama atenção para essa realidade. Segundo Savater: 
Ontem era a valentia que tinha primazia, como todas as faculdades que implicam as culturas militares; hoje em dia é o pensamento e a reflexão; amanhã será, talvez, o refinamento do gosto e a sensibilidade para as coisas da arte. Assim, pois, tanto no presente como no passado nosso ideal pedagógico é, até em seus menores detalhes, obra da sociedade. (SAVATER, 1998, p. 172-173).

O que Savater afirma é que a escala de valores muda forçosamente com as sociedades. E os resultados das mudanças refletem-se em sala de aula, por consequência, os profissionais da educação são convidados a mudar suas práticas pedagógicas. O que acontece atualmente, porém, é que, aos poucos, seja por conta do comportamento dos estudantes, pela falta de material didático, ou pela falta de uma estrutura escolar que se adapte à velocidade das mudanças, os profissionais da educação não conseguem mais avaliar a realidade e o futuro da educação sem que suas angústias sejam expressas.

Diante deste cenário, muitas confusões educacionais são presenciadas. Frente a elas, não faltam posicionamentos que defendem a necessidade em criar algo novo, fazer novas experiências. Entretanto, grande parte dessas pessoas esquece que não é simples a tarefa de criar algo novo antes que se superem velhas estruturas sociais e velhos comportamentos. Essa, aliás, é uma das tarefas que não se realiza da noite para o dia. Sobre isso, ao parafrasear John Dewey, Savater afirma: “[...] os que receberam a educação são os que a dão; os hábitos já engendrados têm uma profunda influência sobre seu procedimento" (SAVATER, 1998, p. 173).

Em meio a esse contexto de transformações rápidas e, algumas delas, radicais, o professor parece pequeno diante de tamanhas mudanças. Na tentativa de mudar, tentar sair da crise e dar respostas aos desafios que se apresentam, os próprios professores se dividem, dependendo do tempo em que estão em sala de aula, é o olhar que cada um tem sobre a educação. $\mathrm{O}$ relato de uma professora prestes a se aposentar é elucidativo: " $\mathrm{Em} \mathrm{um}$ tempo não tão distante, quando se falava em escola, a imagem inicial era: o professor - o púlpito - e o auditório cativo, obrigado 
a escutá-lo. Hoje, o professor continua - o púlpito não - e o auditório não é mais obrigado a escutá-lo”. O problema tirado dessa relação parece ser desafiador, de um lado estão os professores, divididos: alguns grupos de professores sentem saudades da época do púlpito, outros contestam, discordam, mas não sabem o que fazer com os alunos. Outros, ainda, mantêm a esperança de que as coisas vão melhorar; são eles que tentam motivar o grupo dos iniciantes e a ala dos que esperam a aposentadoria. Do outro lado, estão os alunos que criaram ou descobriram seus direitos, fazem exigências e estão dispersos às aulas, tumultuando a prática do professor.

Sem ter propostas claras para administrar todas essas demandas, os órgãos competentes procuram alternativas para melhorar a educação, do conforto das salas climatizadas dos prédios localizados nas capitais, os responsáveis pelo gerenciamento da educação lançam suas soluções. São as experiências que, de uma forma geral, fracassam, ou porque o professor não é qualificado o suficiente para dar uma resposta ao desafio, ou porque a estrutura escolar está aquém daquilo que se imaginou para colocar em prática uma nova proposta.

Assim, os anos vão passando, os profissionais da educação convivendo com uma realidade que está longe de ser satisfatória e os estudantes se acostumando com o que recebem. De vez em quando, alguns números estatísticos chamam a atenção da opinião pública. Nesse momento, os gestores da educação aparecem com outros números e dizem à sociedade que para tudo existe uma explicação. É neste momento que os candidatos a futuros gestores também se manifestam, contestando as observações dos gestores e, desse jeito, a vida segue.

Com a passagem dos anos, temos a convicção de que estamos cada vez mais longe de um passado no qual a razão e a ciência nem sonhavam em ser as fontes em que os saberes se assentam, mas, contrariando esse pensamento, para a surpresa de muitos, em pleno século XXI, a mitologia faz-se presente nas escolas. Narciso, Eco e Sísifo, personagens da mitologia grega, 
fizeram escola e hoje em dia circulam em diferentes espaços de ensino no Brasil, especialmente em escolas de ensino regular.

As reflexões introdutórias são oriundas dos momentos de estudos na Capacitação para professores: educação e prática educativa, promovida pela Universidade Comunitária da Região de Chapecó - Unochapecó -, em parceria com a $4^{a}$ Gerência de Estudos do Estado de Santa Catarina. Nessas capacitações, realizadas nos anos de 2007 e 2008, os professores da rede pública de educação, mais do que se envolver com teorias educacionais e participar de oficinas, usaram o momento para fazer desabafos. Foi a partir desses sintomas e sinais que uma oficina sobre a educação e os mitos foi organizada, tendo como referência os mitos de Eco, Narciso e Sisifo, os professores deram início a uma leitura crítica de suas experiências educacionais, identificando-se ou não com as personagens da mitologia.

\section{A educação e os mitos no século XXI: Narciso, Eco e Sísifo estão na escola}

Em primeiro lugar, é importante dizer que os registros dos relatos aqui apresentados resultam dos debates que aconteceram em coletividade, entretanto, nem tudo o que foi debatido nas manhãs e tardes de estudo pode aqui ser registrado. Duas são as razóes principais para isso, primeiro: não há espaço para dizer tudo o que foi expresso pelos professores, se tudo o que foi dito fosse escrito, somente um livro comportaria todas as falas. Segundo: muitos professores que desejavam falar da educação, não conseguiam. E por que não conseguiam? Algumas respostas: 1) muitos profissionais que desejam falar estavam como $E c o$. Tentavam falar, mas não conseguiam, tinham sido forçados a repetir, repetir, repetir..., depois de um tempo, repetiam com todas as suas forças, mesmo que, conscientemente, negassem; 2) depois de um bom tempo na escola, outros profissionais que desejam falar estavam como Narciso. Durante muito tempo, não 
enxergaram suas imagens, quando começaram a se ver e ver os outros, fugiam deles mesmos e de seus semelhantes, em seguida, voltavam-se a suas teorias e suas disciplinas; 3 ) um terceiro grupo de profissionais da educação manifestou interesse em falar sobre a educação, mas, em seguida, desistiu, afirmaram ser preciso aceitar a tarefa de Sísifo da educação que, de forma pedagógica, consistia em, ano após ano, rolar as pedras educacionais morro acima no início do ano letivo, para que, no fim do ano, elas despencassem ladeira abaixo, dessa forma, no ano seguinte, estariam ali novamente para serem empurradas.

Partindo dessa realidade é que a organização da reflexão acerca da educação, aos poucos, foi se construindo. A curiosidade em torno do que estava acontecendo era tamanha que a necessidade em registrar as declarações surgiu de forma imediata. Despertados para a importância do que estavam afirmando, os professores concordaram em fazer registro daquele momento de estudo para que outras pessoas também soubessem de suas experiências na educação e tudo o que ela envolve. Portanto, a forma da escrita segue o contexto do diálogo. A intenção dos profissionais da educação era fazer um registro da conversa que se mantivesse fiel ao que fora discutido durante os momentos de estudos e debates.

O ponto de partida das análises sobre a educação teve como referência a leitura dos mitos de Narciso, Eco e Sísifo. De acordo com Bulfinch (2001), em O livro de ouro da mitologia, assim aconteceu a história de Eco e Narciso:

Eco era uma bela ninfa, amante dos bosques e dos montes, onde se dedicava a distraçôes campestres. Era favorita de Diana e acompanhava-a em suas caçadas. Tinha um defeito, porém: falava demais e, em qualquer conversa ou discussão, queria sempre dizer a última palavra.

Certo dia, Juno saiu à procura do marido, de quem desconfiava, com razão, que estivesse se divertindo entre as ninfas. Eco, com sua conversa, conseguiu entreter a deusa, até as ninfas fugirem. Percebendo isto, Juno a condenou com estas palavras: 
- Só conservarás o uso dessa língua com que me iludiste para uma coisa de que gosta tanto: responder. Continuarás a dizer a última palavra, mas não poderás falar em primeiro lugar.

A ninfa viu Narciso, um belo jovem, que perseguia a caça na montanha. Apaixonou-se por ele e seguiu-lhe os passos. Quando desejava dirigirlhe a palavra, dizer-lhe frases gentis e conquistar-lhe o afeto! Isso estava fora de seu poder, contudo. Esperou, com impaciência, que ele falasse primeiro, a fim de que pudesse responder. Certo dia, o jovem, tendo se separado dos companheiros, gritou bem alto:

- Há alguém aqui?

- Aqui - respondeu Eco.

Narciso olhou em torno e, não vendo ninguém gritou:

- vem!

- Vem! Respondeu Eco.

- Por que foges de mim? - perguntou Narciso.

Eco respondeu com a mesma pergunta.

- vamos nos juntar - disse o jovem.

A donzela repetiu, com todo ao redor, as mesmas palavras e correu para junto de Narciso, pronta a se lançar em seus braços.

- Afasta-te! - exclamou o jovem recuando. - Prefiro morrer a te deixar possuir-me.

- Possuir-me - disse Eco.

Mas tudo foi em vão. Narciso fugiu e ela foi esconder sua vergonha no recesso dos bosques. Daquele dia em diante, passou a viver nas cavernas e entre os rochedos das montanhas. De pesar, seu corpo definhou, até que as carnes desapareceram inteiramente. Os ossos transformaram-se em rochedos e nada mais dela restou além da voz. E, assim, ela ainda disposta a responder a quem quer que a chame e conserva o velho hábito de dizer a última palavra.

A crueldade de Narciso nesse caso não constituiu uma exceção. Ele desprezou todas as ninfas, como havia desprezado a pobre Eco. Certo dia, uma donzela que tentara em vão atraí-lo implorou aos deuses que ele viesse algum dia a saber o que é o amor e não ser correspondido. A deusa da vingança ouviu a prece e atendeu-a. 
Havia uma fonte clara, cuja água parecia de prata, à qual os pastores jamais levavam rebanhos, nem as cabras monteses frequentavam, nem qualquer um dos animais da floresta. Também não era a água enfeada por folhas ou galhos caídos das árvores; a relva crescia viçosa em torno dela, e os rochedos a abrigavam do sol. Ali chegou um dia Narciso, fatigado da caça, e sentindo muito calor e muita sede. Debruçou-se para desalterar-se, viu a própria imagem refletida na fonte e pensou que fosse algum belo espírito das águas que ali vivesse. Ficou olhando com admiração para os olhos brilhantes, para os cabelos anelados como os de Baco ou de Apolo, o rosto oval, o pescoço de marfim, os lábios entreabertos e o aspecto saudável e animado do conjunto. Apaixonouse por si mesmo. Baixou os lábios, para dar um beijo e mergulhou os braços na água para abraçar a bela imagem. Esta fugiu com o contato, mas voltou um momento depois, renovando a fascinação. Narciso não pode mais conter-se. Esqueceu-se de todo da ideias de alimento ou repouso, enquanto se debruçava sobre a fonte, para contemplar a própria imagem.

- Por que me desprezas, belo ser? - perguntou ao suposto espírito Meu rosto não pode causar-lhe repugnância. As ninfas me amam e tu mesmo não apreces olhar-me com indiferença. Quando estendo os braços, fazes o mesmo, e sorris quando te sorrio, e respondes com acenos aos meus acenos.

Suas lágrimas caíram na água, turbando a imagem. E, ao vê-la partir, Narciso exclamou:

- Fica, peço-te! Deixa-me, pelo menos, olhar-te, já que não posso tocar-te.

Com estas palavras, e muitas outras semelhantes, atiçava a chama que o consumia, e, assim, pouco a pouco, foi perdendo as cores, o vigor e a beleza, que antes tanto encantara a ninfa Eco. Esta se mantinha perto dele, contudo, e, quando Narciso gritava: "Ai, ai", ela respondia com as mesmas palavras. O jovem, depauperado, morreu. E, quando sua sombra atravessou o rio Estige, debruçou-se sobre o barco, para avistar-se na água.

As ninfas o choraram, especialmente as ninfas da água. E, quando esmurravam o peito, Eco fazia o mesmo. Prepararam uma pira funerária, e teriam cremado o corpo, se o tivessem encontrado; em seu lugar, porém, só foi achada uma flor, roxa, rodeada de folhas brancas, que tem o nome e conserva a memória de Narciso ${ }^{1}$.

BULFINCH, 2001, p. 123-127. 
Na mesma obra, a mitologia e as histórias de deuses e heróis, Bulfinch apresenta o mito de Sísifo. A tarefa de Sísifo "[...] consistia em rolar uma enorme pedra até o alto de um morro, mas quando já se encontrava bem avançado na encosta, a pedra, impelida por uma força repentina, rolava de novo para a planície".

Diante disso, "Sísifo a empurrava de novo morro acima, coberto de suor, mas em vão"2.

\section{Eco e os professores repetidores}

Após a leitura dos mitos e um momento de discussão em grupos, os professores começaram a relatar suas conclusões. $\mathrm{O}$ primeiro grupo que fez uso da palavra sintetizou em um cartaz suas conclusões, como título apresentaram: Eco e os imitadores. De acordo com esses professores, assim como Eco, muitos profissionais educadores acostumaram-se a repetir. Nesse sentido, a entrada no século XXI representou a continuidade do século XX, ou seja, a chegada do novo milênio, na visão desses profissionais, foi marcada pela repetição do que se ensinava nas décadas de 1980 e 1990.

Partindo do depoimento desses educadores, fica difícil determinar se há diferenças ou semelhanças entre Eco e os professores. Em uma primeira análise, poderiam ser apontadas diferenças, já que Eco passou a repetir após um castigo recebido de uma deusa da mitologia, e os professores não estão submetidos à mitologia. Entretanto, os professores repetidores ao avaliarem as razões da repetição afirmam que a repetição da qual fazem uso é, também, resultado de um castigo brando que receberam: o não respeito à alteridade humana. Essa violação à dignidade humana, aos poucos, vai transformando-se em uma espécie de castigo ao profissional da educação.

A consequência desse desrespeito é uma aceitação das imposiçôes feitas aos professores. Carentes de uma formação

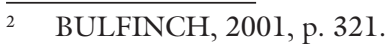


continuada e submissos a uma legislação controladora, os professores, para continuarem sendo professores, aceitam as exigências impostas pelo Estado e continuam dando suas aulas.

Por falta de uma formação continuada que agregue, de fato, uma real valorização ao profissional da educação, os professores repetem o que aprenderam na universidade, independentemente da época em que fizeram suas graduações. Devido a uma pressão disfarçada, somado aos diferentes graus de ingenuidade que os professores carregam, a formação de novas gerações também fica comprometida, pois, agindo dessa forma, os professores reforçam a formação de seres humanos que se tornarão futuros repetidores.

Os professores repetidores formam pessoas repetidoras. A maioria desses profissionais tem consciência disso, mas não consegue superar essa condição. De acordo com relatos, a superação somente acontecerá quando os professores forem vistos e respeitados como profissionais da educação que são e não como inimigos do governo, pessoas que precisam ser castigadas. Parece absurdo, afirmaram os professores, "Mas a impressão que temos é que é isso que o governo do Estado de Santa Catarina pensa de nós".

\section{Narciso e a não interdisciplinaridade}

A interdisciplinaridade faz parte das temáticas que estão constantemente presentes nos debates acerca da educação. Essa foi a primeira observação do segundo grupo de professores ao apresentar suas conclusões. Nas últimas décadas, muito tem se discutido sobre esse assunto. Afirmaram, contudo, que é grande a porcentagem dos professores que continuam ministrando suas disciplinas distantes da interdisciplinaridade, ou seja, o engavetamento e engessamento de conteúdos ainda é muito grande.

A impressão que temos, relataram os profissionais educadores, é que os professores foram embriagados, em outras palavras, estão embebedados de narcisismo. Percebe-se isso através 
do comportamento desses profissionais, cada um acha que a sua disciplina é a mais importante. Nos conselhos de classe, os alunos que não atingiram média em determinadas disciplinas não podem avançar para a próxima série.

Quando alguns professores narcisistas aprovam determinados estudantes que, por alguma razão, não haviam atingido a média em outras disciplinas, os narcisistas chegam a afirmar: "Se ele passou na minha disciplina, como é que vão querer reprová-lo?" Esse argumento é um dos que expressam de forma deliberada como age um professor narcisista.

Realmente, Narciso está na escola, afirmaram alguns professores que acompanhavam a apresentação. Nós não nos damos conta, disseram outros, mas se prestarmos atenção, são vários os momentos que agimos como Narciso. O que acontece, concluiu um dos componentes do grupo que analisou o mito de Narciso, é que, na tentativa de sermos bons, deixamos a nossa disciplina prazerosa, às vezes, somos levados a agir de forma narcisista. E agora, sabemos, isso pode ser prejudicial à educação, pois, no mínimo, implica a não vivência da interdisciplinaridade.

\section{Os professores e a tarefa de Sísifo}

Infelizmente, registraram os professores tarefeiros, essa é a nossa vida, ser como Sísifo. A conclusão desse grupo de professores foi justificada pelo fato de estarem sempre retornando às mesmas experiências. Rolar as mesmas pedras morro acima, bimestre após bimestre, para, ao chegar no topo da montanha, ver a pedra rolar morro abaixo e, em seguida, voltar a subir o morro. É assim que fazem os professores com seus alunos. Diante dessa realidade, porém, alguém poderia perguntar, mas o que fazem vocês para evitar essa terrível tarefa? Para essa pergunta, a resposta poderia ser, discutimos..., no início de cada ano letivo, nós ficamos uma semana discutindo sobre isso, mas não nos damos conta de que até o calendário escolar já está determinado, 
dizendo o que é e o que não é aula. Uma viagem de estudo, por exemplo, em alguns momentos, foi vista como não aula, rolar a pedra morro acima para depois vê-la rolar morro abaixo é aula.

No mesmo sentido, é possível que uma outra pergunta surja a nós, professores, ponderou um educador participante do grupo, é provável que alguém queira saber se nunca desejamos superar a força que impele a pedra a rolar morro abaixo. A essa pergunta poderíamos responder que sim. É claro que já pensamos em descobrir e enfrentar essa força que, além de nos desgastar e deprimir, não contribui para a formação de seres humanos que estão envolvidos conosco nesse processo de ensino aprendizagem. Entretanto, não somos unidos o suficiente para agregarmos força superior a que nos oprime. Existem muitas tentativas isoladas, mas essas não conseguem representar a força necessária capaz de superar a tarefa de Sísifo.

\section{Referências}

BULFINCH, Thomas. O livro de ouro da mitologia: histórias de deuses e heróis: a idade da fábula. 19. ed. Rio de Janeiro: Ediouro, 2001.

SAVATER, Fernando. O valor de educar. São Paulo: Martins Fontes, 1998. 